\title{
Qualidade da graduação: o lugar do assessoramento pedagógico como propulsor da inovação e do desenvolvimento profissional docente
}

\section{Quality of undergraduate courses: the place of pedagogical support as a propellant for innovation and teachers' professional development}

\author{
Maria Isabel da Cunha ${ }^{1}$
}

\begin{abstract}
RESUMO
O texto aborda a emergência da pedagogia universitária no contexto de democratização e expansão da educação superior no Brasil. Salienta a necessária reconfiguração do papel docente e das práticas de ensinar e aprender que tem feito revigorar o campo da pedagogia universitária, debruçando-se sobre as práticas pedagógicas e de reorganização curricular no contexto das mudanças paradigmáticas que assolam a realidade de todo o processo educativo. A expansão tem trazido aos quadros acadêmicos muitos docentes em fase inicial de carreira, que demandam especial atenção. Aposta que o desenvolvimento profissional dos docentes acontece no espaço de trabalho, dada a inexistência de políticas públicas indutoras da formação inicial para esse nível de ensino. Discute que diferentes conceitos de formação produzem distintas estratégias de ação. Apresenta três modelos em ordem decrescente de centralização: (A) Modelo de centralização e controle das ações; (B) Modelo parcial de descentralização e controle das ações; e (C) Modelo descentralizado de acompanhamento e controle das ações. Esses modelos foram usados para analisar os Pressupostos e características dos indicadores, a Compreensão da Formação e do Desenvolvimento Profissional, os Formatos usuais das estratégias de formação e os Formatos de acompanhamento e avaliação.
\end{abstract}

DOI: $10.1590 / 0104-4060.42106$

1 Universidade do Vale do Rio dos Sinos. São Leopoldo, Rio Grande do Sul, Brasil. Av. Unisinos, nº 950, Cristo Rei. CEP: 93022-000.E-mail: mabel@unisinos.br 
Apresenta, ainda, sugestão de estratégias de assessoramento pedagógico que vêm sendo protagonizadas nos espaços acadêmicos.

Palavras-chave: pedagogia universitária; formação; assessoramento pedagógico.

\begin{abstract}
This paper addresses the emergence of higher education pedagogy in the context of democratization and expansion of higher education in Brazil. It points out that the necessary reconfiguration of both the teachers' role and the practices of teaching and learning which have invigorated the field of higher education pedagogy, revisiting pedagogical practices and curricular reorganization, in the context of the paradigmatic changes which have been affecting the reality of the educational processes. Expansion has brought into the academic staffs a number of teachers in the beginning of their careers, condition which demands special attention and actions as to their professional development, which occurs mainly in the workplace. The lack of public policies to trigger initial teacher education is particularly disquieting. In order to develop that discussion we must reflect upon different concepts of teacher education, which produce, respectively, distinct strategies of action. The text introduces three models in descending order of centralization: (A) Model of centralization and control of actions; (B) Model of partial decentralization and control of actions; and (C) decentralized Model of follow-up and control of actions. Such models have been used to analyze the Assumptions and characteristics of the indicators; the Comprehension of Teacher Education and Professional Development; the usual Formats of the strategies of teacher education; and the Formats of follow-up and assessment. Finally, suggestions of strategies for pedagogical support which have been featured in academic spaces are presented.
\end{abstract}

Keywords: higher education pedagogy; teacher education; pedagogical support.

A expansão e a democratização da educação superior no Brasil estão exigindo uma energia especial quer dos governos, quer das comunidades acadêmicas e universitárias. Pressupõem novas alternativas de atuação e uma condição especial para alcançar uma taxa de sucesso positiva na aprendizagem dos novos públicos e na produção de um conhecimento que alavanque melhores índices de desenvolvimento e qualidade de vida.

Trata-se de um panorama que tem provocado reflexões sobre os processos pedagógicos na universidade. A necessária reconfiguração do papel docente e 
das práticas de ensinar e aprender tem feito revigorar o campo da pedagogia universitária, debruçando-se sobre as práticas pedagógicas e de reorganização curricular no contexto das mudanças paradigmáticas que assolam a realidade de todo o processo educativo.

Requer que se aprofunde o conceito de uma didática universitária que, no dizer de Lucarelli (2000), tem como

[...] objetivo a análise do que acontece na aula universitária, estudando onde o processo de ensino que um docente ou uma equipe organiza em relação com as aprendizagens dos estudantes e em função de um conteúdo científico, tecnológico ou artístico, altamente especializado e orientado para a formação de uma profissão. (LUCARELLI, 2000, p. 36).

Essa perspectiva impõe assumir a condição epistemológica própria da pesquisa nos processos de ensino. Ela é que, no espaço da aula, revela a condição da indissociabilidade com a pesquisa e a extensão que precisa estar centrada no estudante, no seu protagonismo em torno do conhecimento. Refere-se a uma possibilidade que também exige saberes específicos da docência, que propicie que os alunos se mobilizem para as aprendizagens. Requer, ainda, uma competência no campo curricular, pois as decisões tomadas nesse âmbito são fulcrais na organização dos saberes e das experiências de formação.

Tanto os estudos sobre a aula como aqueles sobre o campo do currículo da educação superior têm abordado a relação do ensino com a pesquisa. Em recente estudo desenvolvido em universidades brasileiras explicitamos a nebulosa compreensão dessa relação como referente da qualidade da educação superior $(2012)^{2}$. Na representação dos estudantes fica evidente que nem sempre a condição investigativa do professor impacta positivamente nas aulas que ele desenvolve com seus alunos. Algumas vezes até dificulta, porque o professor afina a sua atenção ao campo pesquisado e não ao sentido que o aluno precisa atribuir àquele conhecimento. $\mathrm{E}$, mesmo na visão dos dirigentes acadêmicos, as atividades de ensino e pesquisa acontecem de forma concomitante na universidade, mas não como a condição que a indissociabilidade prevê. Certamente essa perspectiva está também atrelada à escassa compreensão da centralidade do

2 Pesquisa "Qualidade do ensino de graduação: a relação entre ensino, pesquisa e desenvolvimento profissional docente". Projeto desenvolvido com apoio do Conselho Nacional de Desenvolvimento Científico e Tecnológico. (CNPq) e Fundação de Amparo a Pesquisa do Estado do Rio Grande do Sul (FAPERGS). Programa de Pós-Graduação em Educação da Universidade do Vale do Rio dos Sinos (PPGEdu UNISINOS), São Leopoldo, RS, Brasil. 2009-2011. 
conhecimento na organização dos currículos dos cursos, explicitando fragilidades tanto no campo epistemológico como no campo pedagógico.

Essas inferências contribuem para constatar a importância de investir no campo da pedagogia, do currículo e da didática universitária, levando em conta uma construção que precisa compreender os diferentes campos do conhecimento, assim como as culturas institucionais que o albergam.

Esse quadro se mostra com maior emergência no cenário atual, onde se constituíram políticas que favoreceram a incorporação de um contingente significativo de novos docentes. Esses, em sua maioria, apresentam uma condição de formação pós-graduada em nível de mestrado e doutorado. Essa prerrogativa lhes garante certa solidez no domínio dos conhecimentos de suas respectivas áreas e uma boa iniciação à pesquisa. Entretanto, são raras as situações onde a apropriação do conhecimento pedagógico é visível, pois nas suas trajetórias de formação esse conhecimento teve pouco ou nenhuma expressão.

Mencionar, pois, a importância da aprendizagem da docência na trajetória dos professores universitários significa a necessidade de explorar as múltiplas possibilidades e condições para tal, compreendendo que essa formação é multifacetada e se institui na dependência dos contextos temporais, políticos e culturais que as produzem.

A exploração do tema a respeito do desenvolvimento profissional dos docentes da educação superior pressupõe, portanto, distintas possibilidades. Inclui, certamente, o aprofundamento do conceito de formação que ilumina o processo e as decorrências para as práticas institucionais que tenham esse objetivo.

\section{A concepção de formação como referente do desenvolvimento profissional}

Se a concepção de formação não é neutra, torna-se imprescindível analisá-la numa perspectiva que se distancie da compreensão meramente técnica, afastando qualquer possibilidade de negação da subjetividade. Gauthier $(1999$, p. 24) registra, com propriedade, que "[...] cada dispositivo do olhar e da observação modifica o objeto de estudo [...] por isso, nunca estudamos um objeto neutro, mas sempre um objeto implicado, caracterizado pela teoria e pelo dispositivo que permite vê-lo, observá-lo e conhecê-lo".

Nessa perspectiva é importante uma reflexão sistematizada sobre a formação de professores, pois em muitas situações a pesquisa, mesmo considerando sua natural condição questionadora, pode assumir uma contribuição relativa 
para processos educativos emancipatórios. O conhecimento tanto pode ser um lugar de resistência à regulação imposta, como servir de instrumento de poder em um contexto discursivo determinado.

O paradigma da ciência moderna, fortemente inspirador das ciências exatas e naturais, marcou a trajetória das ciências sociais, no seu intento de legitimidade. Nele, muitas vezes, a formação de professores foi tratada numa dimensão eminentemente neutra, quer na sua inspiração pedagógica, quer na perspectiva psicológica.

Assumindo uma posição valorativa explícita, Arroyo (2004, p. 226) defende uma "humana formação", extrapolando a usual interpretação que confina a formação aos espaços e tempos determinados. Para o autor, "[...] a pedagogia nasce quando se reconhece que essa formação, envolvendo a ideia de fabricar o mundo humano, faz parte de um projeto, uma tarefa intencional, consciente". Decorrente e em conformidade com essa posição é possível afirmar que, em sentido amplo, a formação de professores se faz num continuum, desde a sua educação familiar e cultural até a trajetória formal e acadêmica e se mantém como processo vital enquanto acontece seu ciclo profissional. Nesse contexto é possível mencionar um "processo formativo docente" (ISAIA, 2006, p. 351) que engloba "[...] tanto o desenvolvimento pessoal quanto o profissional dos professores, contemplando de forma inter-relacionada ações auto, hetero e interformativas".

Para muitos gestores, o desenvolvimento profissional ainda é responsabilidade individual do professor, que deve responder pela qualidade do seu trabalho. Visto numa perspectiva de formação como capital cultural próprio, se instala numa lógica concorrencial, sem perspectivas de ações coletivas. Os gestores expressam uma compreensão de formação que desconhece o contexto de trabalho como produtor de subjetividades e culturas. Percebem a formação como acumulação de conhecimentos e não como experiência de vida.

Bem distante de seus princípios se institui o conceito de formação como condição de vida, que se dá na trajetória dos sujeitos, a partir dos significados a ela atribuídos. Para haver desenvolvimento profissional é preciso que os sujeitos estejam implicados, assumindo a concepção de autoformação, onde o sujeito exerce o seu arbítrio e interage com os objetivos, artefatos e produtos da própria formação.

Compreender a formação nessa perspectiva requer assumir a experiência como condição da aprendizagem, se tomarmos esse termo na perspectiva de Larrosa (2002), para quem a experiência é o que nos passa, aquilo que sustenta e orienta as nossas ações. Trata-se de um saber, complementa Contreras (2011, p. 58, tradução nossa), que "[...] tem de ser vivido na primeira pessoa e, por isso, é sempre inconcluso, não diz tudo [...] não acaba a frase; tem de ser sempre 
reatualizado, sempre estar à espera de ser acabado para se significar. Um saber como o saber da vida."

As teorias de Schön (1992), Tardif (2002), Nóvoa (1992), Marcelo Garcia (1999) e Gauthier (1999), que valorizam a experiência e a capacidade reflexiva dos professores, reconhecem que eles produzem conhecimentos, ao cotejar a prática com a teoria e o conceito de saberes docentes se instalou num possível contraponto ao sentido dado pelas políticas neoliberais ao termo competências. Essa condição, entretanto, raramente acontece de forma espontânea. Será efetiva se houver um movimento institucional de estímulo e apoio para abrigar a reflexão. Além disso, o processo será bem mais significativo quando partilhado com os pares, compreendendo que os espaços coletivos são produtores das culturas onde os saberes docentes se instituem.

Para que se alcance essa condição, o desenvolvimento profissional docente exige políticas institucionais, que assumam a responsabilidade de propor, acompanhar, estimular e financiar processos formativos que redundem na qualidade da prática pedagógica que desenvolvem. E essa perspectiva estimula olhar atentamente para estes movimentos.

\section{Movimentos institucionais para o desenvolvimento profissional dos docentes da educação superior}

Há algumas décadas tem sido possível localizar investimentos institucionais na formação dos docentes da educação superior. São movimentos que também expressam os valores dos contextos, atingidos pelas políticas públicas e pelas demandas situacionais. Alguns desses movimentos foram registrados e teorizados em estudos e pesquisas, fazendo avançar o conhecimento do campo. Outros ficaram guardados em relatórios e registros parciais. Mesmo reconhecendo diferenças na consolidação dessas experiências, há uma perspectiva geral de que elas são importantes enquanto duram, mas são frágeis nas possibilidades de permanência e pouco se institucionalizam como culturas acadêmicas. Em geral ficam a mercê dos grupos gestores que definem ou não incluir o desenvolvimento profissional dos docentes em suas prioridades. E a cada mudança de gestão, registra-se uma perda do esforço anterior, caracterizando o "desperdício da experiência". (SOUSA SANTOS, 2002).

Em estudo anterior confirmamos que, se a universidade é o espaço da formação dos docentes que nela atuam, dificilmente esses espaços se transformam em lugares, compreendidos como o espaço ocupado por significados dos sujeitos 
envolvidos, ou seja, "[...] quando reconhecemos a sua legitimidade para localizar ações, expectativas, esperanças e possibilidades". (CUNHA, 2010, p. 54). Muito menos transformam-se em territórios, para os quais se teria de contar com o lugar reconhecido e com a estabilidade e "[...] onde se explicitam os valores e dispositivos de poder de quem atribui os significados". (CUNHA, 2010, p. 56).

Também é recorrente o amadorismo que caracteriza as ações institucionais referentes à formação continuada de professores universitários. São poucas as inciativas fundamentadas em reflexões teóricas sobre o sentido da formação, suas condições relacionadas a um adulto que aprende no contexto do trabalho. Muitas vezes, nem mesmo há uma reflexão mais elaborada do conceito de formação que embasa as ações e, como consequência, recorre-se a modelos tradicionais compreendidos como os que assumem perspectivas da racionalidade técnica, sem uma consistente análise de seus resultados e consequências.

Com o intuito de organizar um mapeamento referencial para estudar essas iniciativas, temos nos debruçado sobre a tarefa de organizar indicadores que ajudem a compreendê-las. Essa não é uma tarefa simples, pois, como a maioria dos exercícios que se propõem a capturar a realidade, apresenta complexidades. Trata-se, especialmente, de formulações genéricas, assumindo as restrições que decorrem de exercícios dessa natureza. Não tem a pretensão de realizar enquadramentos definidos, mas de ajudar o exercício de análise de suas propriedades e pressupostos. Para tanto propusemos três modelos em ordem decrescente de centralização: (A) Modelo de centralização e controle das ações; (B) Modelo parcial de descentralização e controle das ações; e (C) Modelo descentralizado de acompanhamento e controle das ações. Esses modelos foram usados para analisar os Pressupostos e características dos indicadores, a Compreensão da Formação e do Desenvolvimento Profissional, os Formatos usuais das estratégias de formação e os Formatos de acompanhamento e avaliação, conforme explicitado abaixo.

\section{Referencial de análise de experiências de formação docente}

\section{1) Pressupostos e características:}

A - Modelo de centralização e controle das ações: Formação com a perspectiva de processos gerais oferecidos a todos os docentes. Decisões sobre os formatos e temas tomadas pelo órgão gestor. Localização episódica. Pouco 
investimento no acompanhamento de percurso. Resultados não controláveis. Descrição quantitativa do envolvimento dos participantes.

B - Modelo parcial de descentralização e controle das ações: Desencadeamento de processos de formação diversificados oferecidos a grupos de docentes em função dos interesses e necessidades. Decisões sobre os formatos tomadas no órgão gestor, mas a partir da perspectiva multirreferencial. Localização temporal, em períodos previamente definidos no calendário acadêmico. Algumas ações de acompanhamento de percurso. Resultados controlados através de metas. Descrição quantitativa e qualitativa do envolvimento dos participantes e dos produtos alcançados.

C - Modelo descentralizado de acompanhamento e controle das ações: Desencadeamento dos processos de formação pelos próprios grupos propositores. Decisões sobre os formatos a cargo dos executores. $\mathrm{O}$ assessor atua como coadjuvante. Registra-se certa autonomia na localização temporal das atividades de formação e formas autogestionárias de acompanhamento. Descrição dependente dos modelos e percursos gestados pelos participantes.

\section{2) Compreensão de formação e desenvolvimento profissional docente:}

A - Modelo de centralização e controle das ações: Formação significa um aporte de informações e de estímulos que acrescentam conhecimentos ao professor. Decorre de propostas externas, de acordo com a visão e interesse da gestão institucional. Aposta de que cada docente é capaz de processar as informações em novos ou melhores saberes. Vê a docência como uma ação individual.

B - Modelo parcial de descentralização e controle das ações: Formação decorre das trajetórias e da reflexão do docente a partir de sua prática, cotejada com a teoria. Envolve mobilização interna, sem desprezar os estímulos externos decorrentes do projeto institucional. Reconhece que os professores são portadores de saberes e é sobre eles que o desenvolvimento profissional se alicerça. Vê a docência como ação compartilhada, sujeita às culturas do campo e das condições objetivas de produção em que vivem.

C - Modelo descentralizado, acompanhamento e controle das ações: Formação é autoformação em que as aprendizagens estão situadas num tempo e lugar, a partir da iniciativa dos docentes. Envolve mobilização interna e autogestão dos processos vividos. Aposta nas iniciativas de grupos docentes mobilizados por algum projeto acadêmico ou político. Assume a supremacia das culturas de campo e suas formas de produção. Definem tempos e espaços de formação. 


\section{3) Formatos usuais das estratégias de formação:}

A - Modelo de centralização e controle das ações: Realização de cursos, oficinas e palestras oferecidos para todos os professores. Escolha de temas e docentes realizada pelo órgão gestor. Em alguns casos as ofertas consideram a possibilidade de escolhas, dentro de uma diversidade de alternativas. Há pouca escuta dos participantes sobre os resultados da formação.

B - Modelo parcial de descentralização e controle das ações: Desenvolvimento de projetos diferenciados atendendo particularidades e interesses grupais e institucionais. Supervisão clínica na forma de acompanhamento. Equipes institucionais organizadas pelas demandas (de Cursos, de Projetos, de Grupos, etc.).

C - Modelo descentralizado, acompanhamento e controle das ações: Estratégias dependem da demanda dos grupos. Cursos pontuais, sessões de estudo, discussão de resultados, registros de campo, pesquisas e resolução de problemas.

\section{4) Formatos de acompanhamento e avaliação:}

A - Modelo de centralização e controle das açães: Avaliação formal por indicadores de presença e controle das ações. Registros quantitativos de estatísticas simples. Preocupação com dar conta aos superiores da tarefa realizada. Avaliação final sem discussão de resultados. Qualidade referenciada na quantidade. Poucas oportunidades de retroavaliação. Quando feita, usa especialmente gráfico ou planilha. Visibilidade institucional.

B - Modelo parcial de descentralização e controle das ações: Preocupação com a avaliação do nível de satisfação dos envolvidos. Toma como referente os objetivos traçados. Modalidades de registro e avaliação dependem da natureza da estratégia e da cultura acadêmica. Acompanhamento de pesquisa, em alguns casos. Uso de dados qualitativos. Registros em relatórios ou em diários de campo. Uso de tecnologias digitais. Preocupação com o tratamento e a socialização dos dados referentes à experiência. Visibilidade institucional.

C - Modelo parcial de descentralização e controle das açães: Estratégias de acompanhamento e avaliação dependem das iniciativas grupais. Utilização, em muitos casos, de meios virtuais de acompanhamento e avaliação interpares. Uso de dados quanti e qualitativos. Resultados dialogam especialmente com o grupo/comunidade envolvida. Interessados em pesquisa e na socialização dos resultados como forma de autossustentação do grupo. Visibilidade prioritariamente para o grupo envolvido ou para os pares.

Tomar esses referentes conceituais de experiências de formação pode ser útil para refletir sobre as ações e os pressupostos que dão sustentação às iniciativas que os desencadeiam. Eles revelam valores e as perspectivas dos 
gestores e grupos de assessoria que coordenam e desencadeiam processos de formação. Deles decorre a possibilidade de inferir sobre o papel e sentido da assessoria e qual seria a dimensão pedagógica que adjetiva a sua ação junto aos docentes e estudantes.

Essa reflexão encaminha a outra mais ampla e complexa: como o Projeto Pedagógico da Instituição de Ensino Superior (IES) se manifesta nas estratégias de formação de seus docentes? Como se expressa na constituição de sua assessoria pedagógica?

O tema das assessorias pedagógicas nas universidades precisa sair do espontaneísmo amador e assumir uma condição profissional. Os estudos realizados sobre as práticas assessoras são escassos e pouco contínuos. Vale ressaltar as iniciativas organizadas por Lucarelli (2000), Mayor Ruiz (2007), Lucarelli e Malet (2010). A Argentina vem realizando Encontros de Assessorias Pedagógicas Universitárias com importante produção e se constitui, a nível ibero-americano, numa referência no campo. No Brasil, as experiências são pontuais e dependentes da sensibilidade dos gestores universitários que ora implementam equipes e programas nesse sentido, ora desativam essas estruturas. São raras as experiências duradouras e consolidadas. Muitas tratam dos professores ingressantes, e/ou programas pontuais de formação continuada. Mas os profissionais que atuam como assessores tem tido pouco reconhecimento acadêmico e não raras vezes há grande rotatividade na prestação desse serviço. Nos últimos anos, em algumas IES Federais, em função do Programa Reestruturação e Expansão das Universidades Federais - REUNI, houve iniciativas mais explícitas, como o caso da Universidade Federal (UF) de Minas Gerais e da UF de Goiás para citar dois exemplos promissores. Também nas Universidades Estaduais se percebe movimentos nesse sentido. São, entretanto, incipientes as condições de estruturação das equipes assessoras.

As assessorias pedagógicas ainda não alcançaram o adequado reconhecimento de seu trabalho no espaço acadêmico e podem ser diversas as explicações para esse fenômeno. A crise de valorização do ensino nas universidades é uma delas. Paradoxalmente essa crise acontece quando os desafios são cada vez maiores para os processos de ensinar e aprender no contexto contemporâneo. Mas, também, a falta de reconhecimento pode ser decorrente do próprio campo pedagógico, que está exigindo renovação, para enfrentar as mudanças culturais e epistemológicas atuais. São aspectos que precisam ser considerados, mas que não neutralizam a importância no investimento nessa importante função. Se os desafios para um ensino de qualidade na universidade são muitos, sem a presença atuante de assessoramento pedagógico eles se multiplicarão.

Esses temas atingem especial significado quando se tem em mente as tarefas próprias dos assessores pedagógicos e a configuração de seus modelos 
de ação. Segundo Fernández (2000), o pedagogo nas instituições educativas contribui com o aumento da eficiência institucional através de um melhoramento de aspectos de organização e formação docente. Muitas vezes isso se faz mediante sua participação na atenção ao conjunto de variáveis que impactam o campo didático e pedagógico, tais como: a especificação dos fins educativos e sua tradução em um modelo didático; as análises das condições dos alunos para desenvolver o processo de aprendizagem; a programação de um currículo que permita alcançar esses objetivos com os alunos; a criação de sistemas de avaliação que permitam a supervisão e o controle das metas desejadas; a preparação de docentes e diretivos para assumir seus papéis e a ajuda aos estudantes, através dos docentes, para ajustar os seus próprios objetivos.

Essas possibilidades têm mobilizado algumas iniciativas institucionais e podem ser importantes aportes para ampliar o referente para o campo da formação continuada de professores e da qualidade da educação superior. Defendemos que a responsabilidade pelo sucesso dos processos de ensinar e aprender precisa extrapolar a visão tradicional de responsabilidade individual do professor. Entendemos que essa condição faz parte das metas institucionais, que precisam atuar em consonância com as políticas públicas mais amplas. Este apoio institucional terá de acontecer em distintos níveis e desde diferentes instâncias e momentos.

Certamente cada instituição assumirá estratégias de acordo com suas trajetórias, compromissos e projetos. Contará para isso a história e cultura dos participantes, as condições objetivas de trabalho, o envolvimento com o projeto coletivo da universidade e as metas a alcançar. A tomada de decisões coletivas sempre favorecerá o compromisso para com o processo. Entretanto, essa condição não dispensa a coordenação e envolvimento institucional que potencializará as energias coletivas para o objetivo maior.

\section{O lugar do assessoramento em pauta: as estratégias e as práticas em ação}

Parece importante explorar alternativas e estratégias que inspirem trajetórias e subsidiem iniciativas institucionais, partindo do pressuposto de que há múltiplas possibilidades, lugares e caminhos. Entretanto, é importante que essa condição não signifique a nebulosidade conceitual e de responsabilidade com os pressupostos da formação. Cada IES, em função de suas culturas, contextos, possibilidades e projetos, assumirá diferentes estratégias. O que importa com- 
preender é que elas não são neutras, universais. Corresponderão inevitavelmente a uma concepção política de educação.

A possibilidade de investigar experiências de assessoramento pedagógico nas instituições de educação superior tem contribuído para o mapeamento de alternativas relativas a essas práticas. Como explicitado neste texto, estas alternativas correspondem a contextos históricos e institucionais e respondem a condições objetivas de funcionamento que caracterizam ou caracterizaram estas instituições em momentos específicos. Também espelham as compreensões teórico-metodológicas relacionadas ao desenvolvimento profissional docente e ao melhoramento das práticas de ensinar e aprender.

Certamente cada experiência traz peculiaridades e um amálgama de possibilidades e contextos que entrelaçam alternativas que se sucedem em tempos e espaços distintos. Os contextos institucionais não são estáveis, nem obedecem a uma mesma forma de regulação. Entretanto, parecem ser importantes os exercícios que se dispõem a cartografar tendências, modelos e possíveis formatos, pois eles ajudam a compreender e a sistematizar nossas próprias idiossincrasias e as possibilidades de realizar sínteses provisórias que nos façam avançar na compreensão do vivido e do que há por viver.

Essa energia é que estimula o exercício de caracterizar algumas estratégias de assessoramento pedagógico presentes nas universidades contemporâneas, que mencionamos a seguir:

- Projetos como estratégia articuladora da ação de assessoramento;

- Editais estimuladores de experiências de formação e inovação;

- Assessorias por Cursos e Áreas numa dimensão clínica;

- Redes de Desenvolvimento e/ou Trajetórias de Formação.

Cada modalidade apresenta algumas características, assumindo que sua complexidade pode dar margem a múltiplas reorganizações, a partir das culturas e possibilidades de cada grupo propositor.

O uso de Projetos como espinha dorsal da ação de assessoria implica usar esse dispositivo para diversificar a proposta de ação, em função das demandas de trabalho e dos interesses dos participantes, em geral docentes da comunidade acadêmica. Há, nessa estratégia, o pressuposto de que é necessário aliar a diversidade da demanda com a intensidade do interesse e disponibilidade dos docentes, o que significa que distintos públicos podem estar envolvidos em diferentes frentes de trabalho, relacionadas com suas expectativas ou condições laborais.

Os Editais como estimuladores de experiências de formação e inovação estão significativamente presentes na cultura acadêmica atual e certamente reproduzem uma prática das agências de fomento que se habituaram à comunidade universitária e às suas culturas. Trata-se de uma ação indutora de melhorias dos 
processos de ensinar e aprender, aliando a distribuição de recursos materiais ao uso pedagógico que deles se faz.

As Assessorias por Faculdades, Cursos, Carreiras e Áreas numa dimensão clínica referem-se a uma estratégia onde o campo científico e/ou profissional se constitui na matriz de organização da ação da assessoria pedagógica. Significa que em cada Faculdade, Curso, Carreira ou Área há um ou mais assessores que atuam junto aos docentes e aos estudantes, apoiando e estimulando ações propositivas de melhorias dos processos de ensinar e aprender. Aproxima-se da concepção da supervisão clínica, que toma a demanda dos docentes ou da Instituição como referente da ação.

As Redes de Desenvolvimento de Práticas e/ou Trajetórias de Formação podem anteceder a institucionalidade das estratégias de assessoramento pedagógico na universidade. De alguma forma, dão contornos ao esforço de melhorar as condições de ensino através da educação continuada, podendo resultar numa estratégia institucional de assessoramento num sentido mais amplo. As modalidades vêm sendo progressivamente desenvolvidas, tanto nos espaços escolarizados como nas organizações corporativas. Decorrem da compreensão de que o desenvolvimento profissional é uma condição da profissionalização e que faz parte da carreira de todos que estão diretamente relacionados com um objetivo de produção, quer de bens, quer de serviços. Têm sido beneficiadas com o advento das tecnologias digitais que sugerem a organização de grupos de discussão e trabalho colaborativo.

Ao explicitar essas quatro estratégias de assessoramente não houve a intenção de esgotar possibilidades, apenas de apresentar algumas delas. Nem de percebê-las isentas de tensões e de subjetividades nas suas proposições. Em todas as alternativas está em jogo o assessoramento como um espaço controvertido que envolve, no dizer de Domingos Segovia (2005, p. 241), “[...] uma questão de saber, poder e identidade". Diz o autor que o trabalho do assessor pedagógico segue sendo de construção subjetiva, de relações inter-pares, "compartindo marginalidades e espaços fronteiriços", que exigem, muitas vezes, que se desconstruam identidades profissionais prévias, para interatuar com cenários alheios " [...] movendo-se sempre entre o ser e o não ser, em âmbitos complexos, construindo um discurso e uma identidade ou posição suspensa em frágil equilíbrio de dimensões bipolares: teoria/prática; desejo/realidade; autonomia/ crítica; assessor/colega [...]". (DOMINGOS SEGOVIA, 2005, p. 242).

O objetivo dessa reflexão foi explorar os pressupostos que sustentam o desenvolvimento profissional docente e as estratégias de assessoramento pedagógico na universidade, tomando como panorama o contexto educacional contemporâneo. Procuramos, principalmente, chamar a atenção para a emergência 
de compreender as estratégias institucionais direcionadas ao desenvolvimento profissional docente no contexto da democratização, expansão e interiorização da educação superior brasileira, alterando a tradicional perspectiva acadêmica alicerçada na meritocracia. Este trabalho quis alertar para um cenário que está a exigir iniciativas propositivas de investimentos nos saberes da docência para que a universidade corresponda ao que dela se espera em termos de qualidade social. Nesse contexto, é importante olhar para a assessoria pedagógica na universidade como uma condição profissional de melhoria e mudança do cenário da educação superior.

\section{REFERÊNCIAS}

ARROYO, Miguel. Oficio de mestre. Petrópolis, RJ: Ed. Vozes, 2004.

CONTRERAS, José Domingos. Experiencia, escritura y deliberación: explorando caminos de libertad en la formación didáctica del profesorado. In: ALLIUD, Andrea; SUÀREZ, Daniel. El Saber de la experiencia. Narrativa, investigación y formación docente. Buenos Aires: CLACSO, 2011. p. 21-86.

CUNHA, Maria Isabel da (Org.). Trajetórias e lugares da formação da docência universitária: da perspectiva individual ao espaço institucional. Araraquara, SP: CNPQ: CAPES: Junqueira \& Marin Editores, 2010.

DOMINGOS SEGOVIA, Jesús. Aportaciones de la investigación biográfico-narrativa al conocimiento de la práctica asesora en educación. In: MONAREO, Carles; POZO; Juan Ignacio. La práctica del Asesoramiento Educativo a Examen. Barcelona: Editorial Graó, 2005. p. 241-252.

FERNÁNDEZ, Lidia. Prólogo. In: LUCARELLI, Elisa (Comp.). El asesor pedagógico en la universidad. De la teoría a la práctica en la formación. Buenos Aires: Paidós, 2000. p. 11-19.

GAUTHIER, Jacques. O que é pesquisar - Entre Deleuze e Guattari e o candomblé. Pensando mito, ciência, arte e culturas de resistência. Educação e Sociedade, ano XX, n. 77, p. 13-33, dez. 1999.

ISAIA, Silvia. Processo Formativo Docente. In: MOROSINI, Marília (Ed.). Enciclopédia da Pedagogia Universitária. Brasília, DF: MEC/INEP, 2006. v. 2. p. 351-405.

LARROSA, Jorge. Notas sobre a experiência e o saber da experiência. Revista Brasileira de Educação, São Paulo, n. 19, p. 20-28, jan./abr. 2002. 
LUCARELLI, Elisa (Comp.). El asesor pedagógico en la universidad. De la teoría a la práctica en la formación. Buenos Aires: Paidós, 2000.

LUCARELLI, Elisa; MALET, Ana Maria (Orgs.). Universidad y prácticas de innovación pedagógica. Estudio de casos en la UNS. Buenos Aires: Jorge Baudino Ediciones, 2010.

MARCELO GARCIA, Carlos. Formação de professores. Para uma mudança educativa. Porto: Porto Editora, 1999.

MAYOR RUIZ, Cristina (Org.). El asesoramiento pedagógico para la formación docente del profesorado universitário. Sevilla: Editora Universidade de Sevilla, 2007.

NÓVOA, António. Os professores e sua formação. Lisboa: Dom Quixote, 1992.

SCHÖN, Donald. La formación de profesionales reflexivos. Barcelona: Paidós, 1992.

SOUSA SANTOS, Boaventura. A crítica da razão indolente: contra o desperdício da experiência. São Paulo: Cortez, 2002.

TARDIF, Maurice. Saberes docentes e formação profissional. Petrópolis, RJ: Vozes, 2002.

Texto recebido em 13 de julho de 2015. Texto aprovado em 17 de agosto de 2015. 
